\title{
DAMPAK SOSIAL EKONOMI PADA KELUAGA TENAGA KERJA INDONESIA YANG BEKERJA DI LUAR NEGERI (STUDI KASUS TKI DI MALASIA)
}

\author{
IDA AYU KETUT MARINI ${ }^{1)}$, IDA BAGUS EKA ARTIKA ${ }^{2)}$, A.A. MADE SURYA KENCANA ${ }^{3)}$ \\ ${ }^{1)}$ Fakultas Pertanian UNMAS Mataram, ${ }^{2.3)}$ Fakultas Ekonomi UNMAS Mataram \\ e-mail, ${ }^{1)}$ yumar4365@gmail.com, ${ }^{2)}$ guseka960@gmail.com, ${ }^{3)}$ aasurya11@gmail.com
}

\begin{abstract}
ABSTRAK
Migrasi tenaga kerja dari suatu negara ke negara lain atau migrasi antar negara di era globalisasi ini menjadi fenomena yang semakin mudah dilakukan oleh tenaga kerja, karena adanya berbagai kemudahan akses yang didukung oleh teknologi, regulasi yang semakin mendukung dan transportasi ke daerah tujuan yang semakin lancar dan terjangkau.

Penelitian ini bertujuan untuk mengetahui dampak sosial dan ekonomi bagi keluarga tenaga kerja Indonesia (TKI) asal Pulau Lombok yang bekerja di Malaysia. Sampel responden berjumlah 70 keluarga TKI yang sedang bekerja di Malaysia, dan wawancara dilakukan terhadap para istri TKI tersebut.

Hasil penelitian menunjukkan bahwa secara sosial, keluarga para TKI yang bekerja di Malaysia dapat meningkatkan kualitas interaksi sosial, memperbaiki tingkat pendidikan anak-anak mereka dengan mengutamakan sekolah anak-anaknya, walaupun dampak negatif secara sosial juga dirasakan oleh istri para TKI yang bekerja di Malaysia melalui pelecehan verbal, dengan julukan "janda Malaysia", digoda oleh lakilaki lain, dikucilkan dan dijadikan bahan gunjingan. Secara ekonomi, keluarga TKI yang bekerja di Malaysia mampu meningkatkan kesejahteraan keluarganya, walaupun semua responden berangkat ke Malaysia dengan modal berhutang, namun setelah mereka mendapat gaji, sebagian gaji yang dikirim kepada para istri mereka digunakan untuk membayar hutang, selain memenuhi kebutuhan ekonomi lainnya yang dapat meningkatkan kondisi perekonomian keluarga mereka. Kepada pemerintah daerah, khususnya pemerintah Provinsi Nusa Tenggara Barat, mengingat bahwa remittance yang dihasilkan oleh para TKI yang bekerja di luar negeri, maka perlu dilakukan program bagi peningkatan kualitas tenaga kerja yang akan dikirim ke luar negeri melalui pemantapan pelatihan-pelatihan kerja bagi calon tenaga kerja Indonesia yang akan dikirim ke luar negeri.
\end{abstract}

Kata kunci : Dampak Sosial Ekonomi, Keluarga Tenaga Kerja Indonesia, Migrasi Tenaga Kerja Indonesia ke Luar Negeri, Remittance.

\section{ABSTRACT}

Labor migration from one country to another or migration between countries in the era of globalization has become an increasingly easy phenomenon for workers, because of the various easy accesses that are supported by technology, increasingly supporting regulations and transportation to destenations which more expedite and more affordable.

This study aims to determine the social and economic impacts on Indonesian workers families (TKI) from Lombok Island who work in Malaysia. The sample of respondents is 70 families of migrant workers who were working in Malaysia, and interviews are conducted with the wives of the migrant workers. The results show that the families of migrant workers who work in Malaysia actually can improve the quality of social interaction, improve the education level of their children by prioritizing their children's schools, although the negative social impact is also felt by the wives of migrant workers working in Malaysia through Verbal abuse, nicknamed "Malaysian widow", seduced by other men, ostracized and made a rumor. Economically, families of migrant workers who work in Malaysia are able to improve the welfare of their families, even though all respondents go to Malaysia are stuck with capital debt, but after they get a salary, some of the salary sent to their wives is used to pay the debts, in addition to fulfilling other economic needs. To the regional government, especially the government of West Nusa Tenggara Province, considering that remittance produced by TKI who work abroad,hence a program is needed to improve the quality of workers who will be sent abroad through strengthening job training for prospective Indonesian workers who will be sent abroad.

Keywords: Socio-Economic Impact, Family of Indonesian Workers, Indonesian Labor Migration Abroad, Remittance. 


\section{PENDAHULUAN}

\section{Latar Belakang}

Persoalan ketenaga kerjaan, merupakan salah satu persoalan yang krusial, yang harus disikapi oleh pemerintah, khususnya dalam menyiapkan lapangan pekerjaan bagi penduduknya, untuk menjamin kelangsungan hidup mereka agar mereka mendapatkan penghasilan, sehingga dapat hidup layak secara ekonomi. Keterbatasan lapangan kerja di suatu daerah mendorong penduduk wilayah tersebut untuk mencari lapangan kerja atau kesempatan kerja di tempat lain, misalnya dari wilayah pedesaan ke wilayah perkotaan, dari satu propinsi ke propinsi lain di wilayah suatu negara atau bahkan dari wilayah suatu negara ke negara lain.

Migrasi tenaga kerja dari suatu negara ke negara lain atau migrasi antar negara di era globalisasi ini menjadi fenomena yang semakin mudah dilakukan oleh tenaga kerja, karena adanya berbagai kemudahan akses yang didukung oleh teknologi, regulasi yang semakin mendukung dan transportasi ke daerah tujuan yang semakin lancar dan terjangkau.Miigrasi tenaga kerja ke luar negeri juga terjadi di berbagai negara, seperti dari Philipina, Vietnam, India dan lain-lain, menuju negara-negara yang memerlukan tenaga kerja yang sesuai dengan keadaan tenaga kerja di negara asal.

Indonesia adalah salah satu negara sebagai penyedia tenaga kerja ke luar negeri dengan tujuan berbagai negara di dunia. Daerah Propinsi Nusa Tenggara Barat, sebagai salah satu propinsi dengan jumlah penduduk 4.955.578 jiwa ( Propinsi Nusa Tenggara Barat Dalam Angka, 2018) juga merupakan salah satu daerah pengirim tenaga kerja ke luar negeri dengan tujuan negara seperti Malaysia, Uni Emirat Arab,Kuwait, Qatar, Hongkong, Korea, Jepang, Brunei Darussalam dan negara lainnya.

Dampak dari adanya tenaga kerja yang bekerja di luar negeri adalah terpisahnya anggota keluarga, karena salah seorang (suami atau isteri) harus pergi bekerja ke luar negeri sedangkan pasangannya (isteri atau suami) harus tinggal di tempat asal untuk menjaga anak-anak dan keluarga. Hal ini tentu akan berimplikasi baik secara soaial maupun ekonomi terhadap keluarga yang ditinggalkan oleh para tenaga kerja Indonesiayang harus bekerja di luar negeri. Ciri khas tenaga kerja Indonesia yang bekerja di luar negeri adalah meninggalkan pasangan dan anak-anaknya di tempat asal, dan pada waktu tertentu tenaga kerja Indonesia tersebut akan pulang kampung untuk kembali pada keluarganya, biasanya pada saat hari raya keagamaan seperti Idul Fitri bagi TKI yang beragama Islam.

Fenomena berbeda terjadi pada migrasi tenaga kerja di daerah Kerala (salah satu negara bagian di India), menurut Zachariah (2001) para tenaga kerja asal Kerala biasanya akan membawa anggota keluarganya untuk beremigrasi dalam mencari pekerjaan di luar negeri, walaupun dalam jangka waktu tertentu mereka akan kembali ke kampung halamannya. Hal ini untuk menghindari dampak sosial negatif yang mungkin terjadi terhadap keluarga, terutama pasangannya (umumnya para isteri) selama para suami bekerja di luar negeri.

Sebagai gambaran, pada tabel 1terlihat bahwa pada tahun 2017, sebanyak 25.787 jiwa penduduk Nusa Tenggara Barat bekerja di luar negeri yang terdiri dari 20.564 tenaga kerja Indonesia laki-laki dan 5.223 tenaga kerja wanita.

Tabel 1 : Jumlah Tenaga Kerja Indonesia Resmi Asal Propinsi Nusa Tenggara Barat Menurut Kabupaten/Kota dan Jenis Kelamin, Tahun 2017.

\begin{tabular}{|l|l|c|c|r|}
\hline No & Kabupaten/Kota & Laki-laki (jiwa) & Perempuan (jiwa) & Jumlah (jiwa) \\
\hline Kabupaten & & & 240 & \\
\hline 1 & Lombok Barat & 3.060 & 899 & 6.908 \\
\hline 2 & Lombok Tengah & 6.009 & 831 & 11.355 \\
\hline 3 & Lombok Timur & 10.524 & 1.896 & 1.931 \\
\hline 4 & Sumbawa & 35 & 65 & 109 \\
\hline 5 & Dompu & 44 & 382 & 573 \\
\hline 6 & Bima & 191 & 498 & 507 \\
\hline 7 & Sumbawa Barat & 9 & 281 & 803 \\
\hline 8 & Lombok Utara & 522 & & 256 \\
\hline Kota & & 98 & 45 \\
\hline 9 & Mataram & 158 & 33 & 25.787 \\
\hline 10 & Bima & 12 & 5.223 & \\
\hline
\end{tabular}

Sumber : Propinsi Nusa Tenggara Barat Dalam Angka, 2018, BPS NTB. 
Jika dicermati, tabel di atas menunjukkan bahwa tenaga kerja Indonesia yang bekerja ke luar negeri lebih banyak dari Pulau Lombok, yaitu sebanyak 22.622 jiwa ( 87,73 \%), dibandingkan dengan tenaga kerja dari pulau Sumbawa yang hanya berjumlah 3.165 jiwa (12,27 \%). Perbandingan antara tenaga kerja laki-laki dengan tenaga kerja wanita juga lebih dominan tenaga kerja laki-laki, karena secara sosial laki-laki merupakan kepala keluarga yang bertanggung jawab untuk menafkahi keluarganya.Hal ini menjadi salah satu alasan, penelitian ini dilaksanakan terhadap tenaga kerja Indonesia laki-laki yang berasal dari Pulau Lombok.

Hal penting lainnya dengan adanya tenaga kerja yang bekerja di luar negeri adalah adanya aliran uang (devisa) yang masuk ke dalam negeri berupa remittance, yang dikirimkan oleh para tenaga kerja Indonesia ke Indonesia untuk menafkahi keluarganya, dimana pada tahun 2017 dana remmitance yang masuk ke Propinsi Nusa Tenggara Barat sejumlah Rp 1.535.391.604.938,77, menurun dibandingkan remittance yang dikirim oleh tenaga kerja Indonesia diluar negeri pada tahun 2016 yang berjumlah Rp.1.780.059.904.247,46. (Propinsi NTB dalam Angka, 2018). Remittance sebanyak itu merupakan dana devisa yang sangat berarti untuk menggerakkan roda perekonomian di wilayah Nusa Tenggara Barat.

Terkait dengan tenaga kerja Indonesia yang bekerja di luar negeri dengan meninggalkan pasangannya di kampung halaman, di Pulau Lombok dikenal adanya istilah "janda Malaysia" yaitu seorang isteri yang ditinggalkan bekerja ke Malaysia oleh suaminya, sehingga masyarakat di sekitarnya menjuluki wanita-wanita yang ditinggal bekerja ke luar negeri, khususnya ke Malaysia, sebagai "janda Malaysia". Wanita yang mendapat julukan "janda Malaysia" secara sosial juga sering menjadi beban bagi wanita tersebut, karena terminasi istilah "janda" secara sosial sering bermakna negatif di masyarakat, sehingga secara social para istri TKI yang bekerja di Malaysia dapat dikatakan mendapat pelecehan secara verbal, namun di pihak lain para istri TKI yang bekerja di Malaysia juga memperlihatkan kemandirian, khususnya dari segi ekonomi setelah mendapatkan kiriman uang dari suami mereka di Malaysia.

\section{Rumusan Masalah}

Dari uraian padalatar belakang di atas, masalah yang dapat dirumuskan permasalahan penelitian ini antara lain :

1). Bagaimana dampak sosial bagi keluarga tenaga kerja Indonesia asal Pulau Lombok yang bekerja di luar negeri, dilihat dari kondisi pendidikan anak-anaknya, peranan isteri yang ditinggal suami selama bekerja di luar negeri dan keadaan sosial lainnya yang terjadi pada keluarganya.

2). Bagaimanadampak ekonomi bagi keluarga tenaga kerja Indonesia asal Pulau Lombok yang bekerja di luar negeri, dilihat dari kontribusi/peranan kiriman uang terhadap perekonomian keluarga, penggunaan uang kiriman, dan peningkatan kesejahteraan keluarga bersangkutan.

\section{Tujuan dan Manfaat Penelitian}

Tujuan penelitia ini adalah untuk mengetahui : 1). dampak sosial bagi keluarga tenaga kerja Indonesia asal Pulau Lombok yang bekerja di luar negeri, dilihat dari kondisi pendidikan anak-anaknya, peranan para isteri yang ditinggal suami selama bekerja di luar negeri dan keadaan sosial lainnya yang terjadi pada keluarganya, 2).dampak ekonomi bagi keluarga tenaga kerja Indonesia asal Pulau Lombok yang bekerja di luar negeri, dilihat dari kontribusi/peranan kiriman uang terhadap perekonomian keluarga, penggunaan uang kiriman, dan peningkatan kesejahteraan keluarga bersangkutan.

Hasil penelitian ini diharapkan sebagai bahan masukan bagi pemerintah daerah terkait di dalam pembuatan kebijakan ketenagakerjaan khususnya di wilayah Pulau Lombok dan Nusa Tenggara Barat pada umumnya.

\section{METODE PENELITIAN}

Metodelogi yang digunakan dalam penelitian ini adalah metode deskriptif, yaitupenelitian yang tertuju pada penggambaran suatu masalah yang ada pada waktu sekarang berdasar pada cara pengumpulan data, menyusunnya, menjelaskannya, menganalisis dan menarik kesimpulan (Surakhmad, 2002, 139). Secara praktis penelitian ini dilakukan melalui pengumpulan dan eksplorasi data primer dan sekunder yang bersumber dari beberapa pihak seperti keluarga yang kepala keluarganya bekerja di Malaysia, data-data 
publikasi yang relevan yang dikeluarkan oleh Badan Pusat Statistik Propinsi Nusa Tenggara Barat dan bacaan lainnya yang relevan.

Lokasi penelitian adalah wilayah Pulau Lombok, yaitu Lombok Barat, Lombok Tengah, Lombok Timur, Lombok Utara dan Kota Mataram. Mengingat jumlah populasi relatif besar, maka metode sampling menggunakan non probability sampling dengan teknik purposive, dimana syarat sampel adalah keluarga TKI yang bekerja di Malaysia, yang berangkat dengan dokumen resmi, dan telah bekerja di Malaysia lebih dari 1 tahun.Pengambilan sampel secara proporsional pada masing-masing wilayah, disesuaikan dengan keperluan. Jumlah sampel yang diambil adalah 70 keluarga TKI yang bekerja di Malaysia, yang diambil dari setiap kabupaten masing-masing sebagai berikut : Lombok Timur 20 responden, Lombok Tengah 15 responden, Lombok Barat 15 responden, Lombok Utara 10 responden dan Kota Mataram 10 responden.

Data dianalisis secara naratif, dengan menganalisis tabel silang (crosstab analysis) berupa data cross section yang terkait dengan tujuan analisis.

\section{HASIL DAN PEMBAHASAN}

\section{Identifikasi Jenis Pekerjaan Kepala Keluarga Sampel}

Jumlah sampel keluarga yang diambil sebanyak 70 keluarga, yang semua kepala keluarganya menjadi tenaga kerja Indonesia di Malaysia, dengan berbagai jenis pekerjaan yang diambil seperti pekerjaladang, cleaning service dan pekerja peternakan dan pekerja industri. Jenis dan jumlah pekerja pada masing-masing jenis pekerjaan diperlihatkan pada tabel 2 :

Tabel 2 : Jenis Pekerjaan dan Jumlah Pekerja Kepala Keluarga Sampel Penelitian

\begin{tabular}{|l|l|r|r|c|c|c|c|}
\hline No & Jenis Pekerjaan & Lotim & Loteng & Lobar & Lombok Utara & Kota Mataram & Jumlah \\
\hline 1 & Pekerja Ladang & 7 & 10 & 6 & 6 & - & 29 \\
\hline 2 & Cleaning Service & 2 & 1 & 3 & - & 2 & 8 \\
\hline 3 & Peternakan & 5 & - & 4 & 1 & 2 & 12 \\
\hline 4 & Pekerja Industri & 6 & 4 & 2 & 3 & 6 & 21 \\
\hline \multicolumn{2}{l}{ Total } & 20 & 15 & 15 & 10 & 10 & 70 \\
\hline
\end{tabular}

Sumber :Data Primer Diolah

Tabel 2 memperlihatkan bahwa sebagian besar tenaga kerja Indonesia asal Pulau Lombok bekerja sebagai pekerja ladang sebanyak 29 orang, diikuti sebagai pekerja di sektor industri berjumlah 21 orang, di bidang peternakan 12 orang dan sebagai cleaning service sebanyak 8 orang. Ini memberikan gambaran bahwa tenaga kerja Indonesia yang bekerja di Malaysia pada umumnya adalah pekerja dengan tingkat pendidikan dan keterampilan relatif rendah. Para tenaga kerja Indonesia memilih bekerja di Malaysia, walaupun jenis pekerjaannya sebagai pekerja kasar, karena tingkat upah di luar negeri relatif lebih tinggi, sehingga ada sisa pendapatan yang bisa dikirim kepada keluarga di kampung halaman.

\section{Kondisi Pendidikan Anak-anak Tenaga Kerja Indonesia}

Semua sampel sepakat bahwa pendidikan untuk anak-anak mereka harus menjadi prioritas, sehingga dari 70 sampel yang diteliti rata-rata anak-anak mereka bersekolah, da tidak ada yang putus sekolah, seperti pada tabel 3 berikut :

Tabel 3: Keadaan Pendidikan Anak-anak Tenaga Kerja Indosesia(TKI )

\begin{tabular}{|l|l|c|c|}
\hline No & Pendidikan Yang Ditempuh & Jumlah (orang)*) & $\%$ \\
\hline 1 & Anak-anak belum sekolah & 11 & 15,72 \\
\hline 2 & TK & 17 & 24,29 \\
\hline 3 & SD & 8 & 11,43 \\
\hline 4 & SMP & 12 & 17,14 \\
\hline 5 & SMA & 18 & 25,71 \\
\hline 6 & Perguruan Tinggi & 4 & 5,71 \\
\hline \multicolumn{2}{|l|}{ To t a l } & 70 & 100,00 \\
\hline
\end{tabular}

Sumber : Data Primer Diolah

Catatan * :Jika memiliki 2 anak atau lebih, yang diteliti adalah pendidikan anaknya yang paling tinggi 
Pendidikan anak-anak tenaga kerja Indonesia secara umum menjadi perhatian penting bagi keluarga, dimana terdapat 11 keluarga yang masih memiliki anak yang belum bersekolah karena usianya masih balita, kemudian 17 keluarga memiliki anak-anak bersekolah di sekolah dasar, 8 keluarga anaknya bersekolah di sekolah dasar, 12 keluarga anaknya bersekolah di SMP, 18 keluarga memiliki anak yang bersekolah di SMA dan 4 keluarga telah memiliki anak yang kuliah di perguruan tinggi. Dari segi pendidikan formal, anak-anak dari tenaga kerja Indonesia diutamakan untuk mendapatkan pendidikan yang baik, agar nantinya mereka bisa mendapatkan peluang mendapatkan pekerjaan yang lebih baik.

\section{Kegiatan yang dilakukan Isteri Tenaga Kerja Indonesia selama ditinggal bekerja di Malaysia}

Ada beberapa jenis aktivitas yang biasanya dilakukan oleh para istri yang ditinggal bekerja ke Malaysia oleh suaminya, seperti mengasuh anak 7 orang (10\%), membantu pekerjaan mertua/orang tua sebanyak 32 orang $(45,71 \%)$, bekerja sebanyak 19 orang $(27,14 \%)$ dan berdagang sebanyak 12 orang $(17,15$ $\%)$. Bagi para istri yang memiliki anak yang masih balita atau bayi, maka mereka lebih banyak menghabiskan waktu untuk mengasuh anaknya. Namun jika anak-anak mereka sudah tidak perlu diasuh (dijaga), maka mereka dapat membantu pekerjaan mertua yang memiliki mata pencaharian bertani, beternak atau berdagang. Ada juga para wanita yang bekerja baik di perusahaan swasta maupun sebagai aparatur sipil negara, dan terakhir ada juga yang menekuni profesi sebagai pedagang.Data kegiatan para wanita istri TKI dapat dilihat pada tabel 4 .

Tabel 4 : Kegiatan para istri Tenaga Kerja Indonesia(TKI) selama ditinggal Bekerja di Malaysia

\begin{tabular}{|l|l|c|c|}
\hline No & Jenis Kegiatan & Jumlah (orang) & $\%$ \\
\hline 1 & Mengasuh anak & 7 & 10,00 \\
\hline 2 & Membantu mertua/orang tua & 32 & 45,71 \\
\hline 3 & Bekerja & 19 & 27,14 \\
\hline 4 & Berdagang & 12 & 17,15 \\
\hline \multicolumn{2}{|c|}{ T o t a l } & 70 & 100,00 \\
\hline
\end{tabular}

Sumber : Data Primer Diloah

\section{Perlakuan bersifat positip dan negatif yang dialami wanita istri TKI}

Dari semua sampel yang diteliti, sebagian besar wanita istri tenaga kerja Indonesia yang ditinggal bekerja di Malaysia menyatakan bahwa perlakuan masyarakat pada umumnya cenderungbersifat negatif dibandingkan dengan perlakuan yang positif terhadap mereka. Hampir semua dari mereka pernah mengalami pelecehan secara verbal dengan sebutan "janda Malaysia" atau jamal, sering digoda pria lain, dan perlakuan yang kurang menyenangkan, seperti menjadi bahan gunjingan dan dikucilkan dari pergaulan baik dari keluarga dekat maupun masyarakat di sekitar. Sedangkan perlakuan positip juga ada berupa dukungan moril, mendoakan, memberikan motivasi dan memberikan nasehat, biasanya datang dari teman dekat, saudara dan orang tua kandung.Perlakuan positip dan negatif yang dialami istri TKI selama ditinggal bekerja di Malaysia dapat dilihat pada tabel 5:

Tabel 5: Perlakuan Positip dan Negatif yang Dialami istri Tenaga Kerja Indonesia(TKI) selama ditinggal bekerja di Malaysia

\begin{tabular}{|l|l|c|c|}
\hline No & Jenis Perlakuan & Jumlah (orang) & $\%$ \\
\hline 1 & Mendukung secara moril (positip) & 36 & 51,43 \\
\hline 2 & Mendoakan (positip) & 66 & 94,29 \\
\hline 3 & Memberi motivasi (positip) & 12 & 17,15 \\
\hline 4 & Menasehati (positip) & 7 & 10,00 \\
\hline 5 & Pelecehan verbal/dijuluki janda Malaysia (negatif) & 68 & 97,14 \\
\hline 6 & Digoda laki-laki lain, diajak nikah (negatif) & 54 & 77,14 \\
\hline 7 & Dikucilkan dari pergaulan (negatif) & 5 & 7,14 \\
\hline 8 & Menjadi bahan gunjingan (negatif) & 24 & 34,29 \\
\hline
\end{tabular}

Sumber : data Primer, diolah 
Pada tabel di atas, tidak dibuatkan penjumlahan karena pertanyaan bersifat terbuka dan antar pertanyaan kepada responden tidak saling meniadakan, sehingga beberapa perlakuan dapat dialami oleh seorang responden sekaligus.

\section{Penggunaan Uang yang Dikirim Suami dari Tempat Bekerja}

Kondisi perekonomian yang sulit merupakan salah satu faktor yang mendorong para tenaga kerja Indonesia untuk mencari pekerjaan di luar negeri, walaupun untuk mendapatkan pekerjaan kasar seperti berladang, bekerja di peternakan, cleaning service dan lainnya. Pendapatan yang relatif lebih tinggi di luar negeri, diharapkan akan dapat dikirim kepada keluarga di kampung untuk memperbaiki keadaan ekonomi keluarga, sebagai cara untuk memotong rantai kemiskinan yang menjerat mereka selama ini.

Penggunaan uang kiriman para TKI yang bekerja di Malaysia oleh para istrinya, digunakan untuk berbagai macam keperluan, terutama adalah untuk membayar hutang karena untuk keberangkatan para tenaga kerja Indonesia (TKI) tersebut biasanya dilakukan dengan modal berhutang, semua responden (100\%) yang diwawancara menyatakan bahwa kiriman uang dari suami mereka digunakan untuk membayar hutang, yang berarti bahwa mereka bekerja ke luar negeri dengan biaya berhutang. Selain membayar hutang, kiriman uang dari suami mereka juga digunakan untuk membiayai kebutuhan sehari-hari (100\%), biaya anak sekolah $(82,86 \%)$, membeli barang-barang perlengkapan rumah tangga $(85,71 \%)$, membeli perhiasan (100\%), kedit motor $(80 \%)$, memperbaiki rumah $(52,86 \%)$, membeli tanah $(11,43 \%)$, ditabung $(14,29 \%)$ dan untuk keperluan biaya sosial kemasyarakatan (100\%), seperti ditampilkan pada tabel 6 berikut :

Tabel 6: Penggunaan uang Kiriman Suami oleh istri Tenaga Kerja Indonesia (TKI) yang bekerja di Malaysia

\begin{tabular}{|c|l|c|c|}
\hline No & Jenis Penggunaan Uang & Jumlah (orang) & $\%$ \\
\hline 1 & Membayar hutang & 70 & 100,00 \\
\hline 2 & Memenuhi kebutuhan sehari-hari & 70 & 100,00 \\
\hline 3 & Biaya anak sekolah anak & 58 & 82,86 \\
\hline 4 & Membeli perlengkapan rumah tangga & 60 & 85,71 \\
\hline 5 & Membeli perhiasan & 70 & 100,00 \\
\hline 6 & Kredit motor & 56 & 80,00 \\
\hline 7 & Memperbaiki rumah & 37 & 52,86 \\
\hline 8 & Membeli tanah & 8 & 11,43 \\
\hline 9 & Ditabung & 10 & 14,29 \\
\hline 10 & Biaya sosial kemasyarakatan & 70 & 100,00 \\
\hline
\end{tabular}

Sumber : Data Primer Diolah

Dari penggunaan uang kiriman ini, terlihat bahwa keluarga TKI yang ditinggal bekerja di Malaysia benar-benar dimanfaatkan untuk memenuhi kebutuhan dasar, kemudian ada sebagian berusaha untuk memperbaiki rumah, membeli tanah dan bahkan menabung, dengan harapan di masa mendatang ada harapan untuk terus meningkatkan kesejahteraan keluarga mereka.

Dengan adanya kiriman uang bagi istri tenaga Kerja Indonesia (TKI) yang bekerja di Malaysia, secara ekonomi keluarga mereka merasa lebih sejahtera, merasa lebih mandiri dan bahkan ada yang memiliki tabungan sebagai bekal untuk berjaga-jaga di kemudian hari.

\section{SIMPULAN DAN SARAN}

\section{Simpulan}

Dari pembahasan hasil penelitian di atas, dapat disimpulkan hal-hal terkait permasalahan yang ingin dipecahkan sebagai berikut :

1. Secara sosial, keluarga para TKI yang bekerja di Malaysia dapat meningkatkan kualitas interaksi sosial, memperbaiki tingkat pendidikan anak-anak mereka dengan mengutamakan sekolah anak-anaknya, walaupun dampak negative secara social juga dirasakan oleh istri para TKI yang bekerja di Malaysia melalui pelecehan verbal, dengan julukan "janda Malaysia", digoda oleh laki-laki lain, dikucilkan dan dijadikan bahan gunjingan.

2. Secara ekonomi, keluarga TKI yang bekerja di Malaysia mampu meningkatkan kesejahteraan keluarganya, walaupun semua responden berangkat ke Malaysia dengan modal berhutang, namun setelah mereka mendapat gaji, sebagian gaji yang dikirim kepada para istri mereka digunakan untuk membayar 
hutang, selain memenuhi kebutuhan ekonomi lainnya yang dapat meningkatkan kondisi perekonomian keluarga mereka.

\section{Saran-saran}

Kepada pemerintah daerah, khususnya pemerintah Provinsi Nusa Tenggara Barat, mengingat bahwa remittance yang dihasilkan oleh para TKI yang bekerja di luar negeri, maka perlu dilakukan program bagi peningkatan kualitas tenaga kerja yang akan dikirim ke luar negeri melalui pemantapan pelatihan-pelatihan kerja bagi calon tenaga kerja Indonesia yang akan dikirim ke luar negeri.

\section{DAFTAR PUSTAKA}

BPS NTB, 2018, Capaian PembangunanNTB Dalam Guratan Data, Badan Pusat Statistik Propinsi Nusa Tenggara Barat

.........., 2019, Nusa Tenggara Barat Dalam Angka 2018, Badan Pusat Statistik Propinsi Nusa Tenggara

Barat

2019, Statistik Gender Nusa Tenggara Barat 2018, Badan Pusat Statistik Propinsi Nusa Tenggara

Barat

Eka Artika, Ida Bagus, dkk, 2018, Pergeseran Lapangan Usaha Sektor Pertanian, Pertumbuhan Ekonomi Dan Penurunan Tingkat Kemiskinan di Propinsi Nusa Tenggara Barat, Jurnal Ganec Swara, Vol. 12, No. 1, Maret 2018, ISSN 1978 - 0125 (Print); ISSN 2615 -8116 (Online), Universitas Mahasaraswati Mataram,.

Murni, Asfia, 2006, Ekonomika Makro, Penerbit PT Rafika Aditama, Bandung.

Priyono, 2017, Memperkuat Momentum, Sambutan Kepala Perwakilan Bank Indonesia Propinsi Nusa Tenggara Barat Dalam Pertemuan Tahunan Bank Indonesia 2017, Bank Indonesia Propinsi Nusa Tenggara Barat.

Surakhmad, Winarno, 2002, Metode Penelitian, Penerbit Tarsito, Bandung.

Tambunan, Donald, 1999, Pergeseran Tenaga Kerja Muda dari Sektor Pertanian ke Luar Pertanian dan Fenomena Migrasi Akibat Pembangunan Industri di Pedesaan (Kasus : Desa Bitung Sari, Kecamatan Ciawi, Kabupaten Bogor), Institut Pertanian Bogor

Zachariah K.C and S. Irudaya Rajan, 2001, Gender Dimensions of Migration in Kerala : Macro and Micro Evidence, Asia Pasific Population Journal, Vol. 16 No. 3, September 2001 (ISSN 0259 -238X). 